Australian

National

University

Crawford School of Public Policy

\title{
CAMA
}

Centre for Applied Macroeconomic Analysis

\section{European Equity Investing through the Financial Crisis: Can Risk Parity, Momentum or Trend Following Help to Reduce Tail Risk?}

\section{CAMA Working Paper 8/2014 January 2014}

Andrew Clare

Cass Business School, City University London

\section{James Seaton}

Cass Business School, City University London

\section{Peter N. Smith}

University of York and

Centre for Applied Macroeconomic Analysis

\section{Stephen Thomas}

Cass Business School, City University London 


\section{Abstract}

A growing body of literature suggests that over widely varying historical eras and across a wide range of asset classes momentum investing, often accompanied by a trend following overlay, provides superior risk-adjusted returns. We examine the effectiveness of applying these methodologies to pan-European equity asset allocation through periods of potentially substantial market dislocation, in particular, with the advent of the single currency and the equity market crashes of the early 2000"s and 2008.With the introduction of the Euro there has been much discussion of the benefits of diversification via country based portfolios versus industry sector portfolios. Early studies simply looked at changing return correlations over time. The simple conclusion that increasing country correlations over time drives superior risk-adjusted portfolios towards diversification across sectors has been increasingly challenged. Our approach is different in that we apply momentum and trend following investing strategies and assess whether it is sectoral or country indices which dominate our portfolios through periods of structural changes and extreme volatility. Diversification via sectors is clearly the best strategy in times of equity market stress. In addition, the application of trend following offers a substantial improvement in risk-adjusted performance compared to traditional buy-andhold portfolios. The terms momentum and trend following have often been used interchangeably although the former is a relative concept and the latter absolute. By combining the two we find that one can achieve the higher return levels associated with momentum portfolios but with much reduced volatility, tail risk and drawdowns due to trend following. We observe that a flexible asset allocation strategy that allocates capital to the best performing instruments irrespective of asset class enhances this further. Such methodologies offer superior risk adjusted returns, especially through periods of raised market volatility.

\section{Keywords}

Trend following, Momentum investing, tail risk, European equity sectors, Financial Crisis

\section{JEL Classification}

\section{Address for correspondence:}

(E) cama.admin@anu.edu.au

The Centre for Applied Macroeconomic Analysis in the Crawford School of Public Policy has been established to build strong links between professional macroeconomists. It provides a forum for quality macroeconomic research and discussion of policy issues between academia, government and the private sector.

The Crawford School of Public Policy is the Australian National University's public policy school, serving and influencing Australia, Asia and the Pacific through advanced policy research, graduate and executive education, and policy impact. 


\title{
European Equity Investing through the Financial Crisis: Can Risk Parity, Momentum or Trend Following Help to Reduce Tail Risk?
}

\author{
Andrew Clare*, James Seaton*, Peter N. Smith† and Stephen Thomas* \\ *Cass Business School, City University London \\ †University of York, CAMA
}

This Version: December 2013

\begin{abstract}
$\underline{\text { Abstract }}$
A growing body of literature suggests that over widely varying historical eras and across a wide range of asset classes momentum investing, often accompanied by a trend following overlay, provides superior risk-adjusted returns. We examine the effectiveness of applying these methodologies to pan-European equity asset allocation through periods of potentially substantial market dislocation, in particular, with the advent of the single currency and the equity market crashes of the early 2000's and 2008. With the introduction of the Euro there has been much discussion of the benefits of diversification via country based portfolios versus industry sector portfolios. Early studies simply looked at changing return correlations over time. The simple conclusion that increasing country correlations over time drives superior risk-adjusted portfolios towards diversification across sectors has been increasingly challenged. Our approach is different in that we apply momentum and trend following investing strategies and assess whether it is sectoral or country indices which dominate our portfolios through periods of structural changes and extreme volatility. Diversification via sectors is clearly the best strategy in times of equity market stress. In addition, the application of trend following offers a substantial improvement in risk-adjusted performance compared to traditional buy-and-hold portfolios. The terms momentum and trend following have often been used interchangeably although the former is a relative concept and the latter absolute. By combining the two we find that one can achieve the higher return levels associated with momentum portfolios but with much reduced volatility, tail risk and drawdowns due to trend following. We observe that a flexible asset allocation strategy that allocates capital to the best performing instruments irrespective of asset class enhances this further. Such methodologies offer superior risk adjusted returns, especially through periods of raised market volatility.
\end{abstract}

Key words: Trend following; Momentum investing; tail risk; European equity sectors, Financial Crisis. 


\section{Introduction}

Should international equity investors and asset allocators seeking optimal diversification in European equities focus on diversifying across industries or countries? This question has been exhaustively investigated in the context of the introduction of the single European currency and effectively considering long only investment in sectoral or country indices. Far more realistic and superior risk adjusted return strategies include those incorporating momentum, trend following and risk parity investing, and potentially involving a changing mix of sectors and countries through time. Hence we ask the following question: how does the relative importance of sectors and countries evolve in the construction of portfolios through major changes such as the arrival of the Euro or the equity market volatility of the early 2000's or 2008? Are conventional ideas on the relative importance of countries and sectors in the diversification process robust to the changing environment?

The accepted view for nearly 30 years since the pioneering work of Levy and Sarnat (1970), Solnik (1974) and Lessard (1976) has been that such diversification is best achieved by spreading one's investment across countries but this has been increasingly challenged over the last decade in which the removal of currency risk within a large part of Europe may suggest otherwise. The introduction of the Euro has effectively eliminated intra-Eurozone currency uncertainty and the foreign exchange risk exposure of these countries has accordingly decreased (Bartram and Karolyi, 2006). Currency risk premia are large and economically significant (De Santis and Gerard, 1998) and different exchange rate exposures across countries lead to varying currency risk premia and hence possibly lower cross-country correlations. Hence the removal of currency risk in the Eurozone could well induce higher correlations between these countries, and consequently reduce the benefits of cross-country diversification. Such a rise in correlations between countries is also noted by Adjaoute and Danthine (2004).

In this paper we compare portfolios comprised of both industry and country indices separately and combined based upon momentum and trend following selection techniques and show the substantial risk reduction benefits accruing to combining the methods (see ap Gwilym et al, 2010, Clare et al, 2012).We are particularly concerned with the tail risk associated with various strategies, which can impose such large losses on investors as to render these strategies completely unsustainable in practice due to margin calls. Gray and Vogel (2013) show clearly how maximum drawdown can be useful as a metric for tail risk. 
In assessing the merits of diversification by industry or country early studies simply focussed on the changing correlations of returns. However, these may be misleading as country indices contain both country and sector effects and a low correlation between two country indices which suggests a segmentation of their markets with national elements dominating could be simply because they comprise very different industry sectors. We need to compare country indices without sector biases (and indeed vice versa). Baca et al (2000), using monthly country returns for 10 sectors and the 7 largest countries (by market cap) between 1979-1999, finds that country effects have dominated historically but that this shifted to roughly 50/50 by the end of the period. This suggests increased global capital market integration with the implication that country-based approaches to global investment management may be losing their effectiveness. Similarly Cavaglia et al (2000), with a sample of 21 developed countries and 36 sectors for the period 1986-1999, use a factor model to show that industry effects had become an increasingly important component of returns (relative to country factors). However Hargis and Mei (2006) challenge this view by decomposing the sources of industry and country diversification into cash flow and discount rate drivers and find that global factors are much less important for return components at country level than industry level; hence better diversification of underlying cash flows is achieved by country diversification.

A natural context for the discussion of changing country versus industry effects is the advent of EMU and the single European currency. Ferreira and Ferreira (2006) find that nominal convergence post-EMU has indeed reduced the differences between national equity markets and that over the period 1975-2001 sector effects became more important relative to country effects. After the introduction of the Euro a fall in the ratio of industry to country effects can be explained by the fall in cross-sectional variance of interest rate changes across Europe. Using panel data and building on the Heston and Rouwenhorst (1995) approach, Flavin (2004) looks at the relative benefits of sectoral versus geographical diversification in the Eurozone before and after the introduction of the common currency; the study supports the $a$ priori expectation that a rise in the correlation of markets would lead to a move towards sector diversification; the effect is also present for non-EMU European countries so fund managers should pursue sectoral rather than country diversification.

A rather different approach is taken by Bekaert et al (2010) who use industry valuation differentials to study the impact of membership of both the European Union and the single European currency. Their novel approach focuses on the fact that in integrated markets both discount rates and expected cash flows (i.e. growth opportunities) should be similar within 
any given industry independent of country of location. This implies a convergence of valuation differentials as countries become more integrated and this will be empirically seen in their respective PE ratios. Bekaert et al find that membership of the EU significantly reduced differentials across countries whereas adoption of the Euro was not associated with increased integration. Finally an intuitively appealing approach is to conduct a style analysis of returns: Eiling et al (2012) find that country effects dominate returns prior to the advent of the Euro whereas industry effects become more important after 1999. They find that this effect is magnified dramatically during periods of equity market stress with sectoral indices showing strong dominance particularly in 2002-03 and after 2007.

To anticipate our conclusions, we find that within the construction of momentum portfolios, sectors clearly dominate countries during periods of extreme volatility though the introduction of the Euro itself seems to have much less impact on the relative importance of sectors versus countries in the preferred, superior risk-adjusted portfolios.

It is possible that the unconditional differences in returns can be explained by exposure to risk factors. We show that this is not the case for the strategy returns we examine and for the two groups of risk factors that we consider. Indeed, in the more general case, the alphas that remain are at least as large as in the unconditional case. An important issue in examining the performance of any investment strategy over the last few years is the importance of downside risk and the exposure of strategy returns to factors associated with downside risk. Daniel and Moskowitz (2011) and Daniel et al (2012) have shown that momentum strategy returns are often skewed and are subject to momentum crashes where momentum portfolio returns fall abruptly following a downturn in the market overall. We examine the importance of these effects for the period we examine and find that momentum returns, as well as the index returns themselves, were subject to significant negative skewness and large maximum drawdown. We also show that this is not the case for strategies that also employ the trend following filter. The second issue to examine is the possible causes of this left tail skewness. We examine the sensitivity of returns to funding liquidity effects as measured by a world version of the TED spread. We show that momentum and index returns are significantly negatively related to funding illiquidity. Models that also employ the trend following filter are not significantly associated with funding illiquidity. The use of cash investments when the trend following filter is negative provides a potential escape from the impact of illiquidity which appears more important for momentum strategies that require short selling of assets with previously negative returns. 
In section 2 we describe our approach to momentum and trend following and as ways of forming portfolios while in section 3 we present our initial results. In section 4 we examine whether the differences in returns can be explained using a range of risk factors and the issue of downside risk. We conclude in section 5.

\section{Momentum and Trend Following}

Momentum is one anomaly in the financial literature that has been demonstrated to offer some explanatory ability of future returns. Many studies, such as Jegadeesh and Titman (1993) and Grinblatt and Moskowitz (2004) have focussed on momentum at the individual stock level, whilst others such as Miffre and Rallis (2007) and Erb and Harvey (2006) have observed the effect in commodities. Asness et al (2010) find momentum effects within a wide variety of asset classes, whilst King et al (2002) use momentum as a means of allocating capital across asset groups.

Typical momentum strategies involve ranking assets based on their past return (often the previous twelve months) and then buying the winners and selling the losers. Ilmanen (2011) argues that this is not the ideal approach and that investors would be better served by volatility weighting the past returns. Failing to do this leads to the most volatile assets spending a disproportionate amount of time in the highest and lowest momentum portfolios (see Asness et al, 2010).

Trend following has been widely used in futures markets, particularly commodities, for many decades (see Ostgaard, 2008). Trading signals can be generated by a variety of methods such as moving average crossovers and breakouts with the aim to determine the trend in prices. Long positions are adopted when the trend is positive and short positions, or cash, are taken when the trend is negative. As trend following is generally rules-based it can aid investors since losses are mechanically cut short and winners left to run. This is frequently the reverse of investors' natural instincts. The return on cash is also an important factor either as collateral in futures or as the risk-off asset for long-only methods. Examples of the effectiveness of trend following are, amongst others, Szacmary et al (2010) and Hurst et al (2010) for commodities, and Wilcox and Crittenden (2005) and ap Gwilym et al (2010) for equity indices. Faber (2007) uses trend following as a means of tactical asset allocation and demonstrates that it is possible to form a portfolio that has equity-level returns with bond- 
level volatility. Ilmanen (2011) offers a variety of explanations as to why trend-following may have been successful historically, including investor underreaction to news and herding behaviour. Moskowitz et al (2011) refer to an equivalent of trend following as "time series momentum". They demonstrate that a variety of asset classes show persistence in returns for periods of 1-12 months.

A few studies have sought to combine some of the strategies previously discussed. Faber (2010) uses momentum and trend following in equity sector investing in the United States. Antonacci (2012) uses momentum for trading between pairs of investments and then applies a quasi-trend following filter to ensure that the winners have exhibited positive returns. The risk-adjusted performance of these approaches has been a significant improvement on benchmark buy-and-hold portfolios. In a related study we extend these ideas to the multiasset context (Clare et al, 2012) and find the following:

- Adding a momentum filter increases the level of return compared to equal weighting and offers somewhat higher risk-adjusted performance. Momentum portfolios are prone to large drawdowns, however.

- Trend following portfolios are a further improvement with higher Sharpe ratios and lower maximum drawdowns. This is the case both in multi-asset portfolios and within asset classes.

- Combining momentum and trend following within asset classes gives considerably higher returns than equal weightings, although the risk-adjusted performance is broadly similar to pure trend following portfolios. Adding momentum is thus useful for investors wishing to aim for higher return levels but with an aversion to leverage.

- A flexible asset allocation strategy with trend following that ranks all assets according to their volatility-weighted momentum has shown a consistent high level of return. This method has the attractive quality of not requiring any asset allocation weights to be predetermined.

- The additional higher returns achieved by these strategies are not explained by commonly employed risk factors.

The present study applies these methods to the European equity context with 19 panEuropean equity sectors and 15 country indices (see section 3 below). Specifically, we ask the following questions: 
i) Does trend following and momentum investing yield similar improvements in risk-adjusted returns for European equity investing?

ii) What is the relative importance of sectors versus country returns in forming the 'best' momentum portfolios over time? Is there a significant change post introduction of the single currency?

iii) Is there a 'best' strategy which preserves equity wealth through the recent financial crisis?

\section{Empirical Results}

\subsection{Full period analysis}

Our data set comprises monthly total returns across Europe by sector and country. The data are monthly for the period 1988-2011. The 19 sector indices are for the Stoxx 600 and the 15 country indices are MSCI (see Table 1). All returns are net total returns in USD, gross of transactions costs. Table 2 contains the basic summary statistics for standard and equally weighted indices for the returns in Table 1: the formidable volatility of equity markets in this period is clearly seen in the near $60 \%$ maximum drawdown across all formulations. In fact both equal and market weighted returns are very similar for this period, as indeed is volatility and risk-adjusted returns (Sharpe ratios of around 0.22-0.29). Each of the standard indices and equally weighted versions of the indices show similarly negative skewness over the period we analyse. We report $\pi$, the Bai-Ng (2005) test for negative skewness finding that these returns are significantly negatively skewed at the $95 \%$ level. $^{1}$

We now seek to construct momentum strategies for sectors and countries separately (see Table 3).We present results for a variety of long-only portfolios, comprising the top 8 and top 4 ranked countries and sectors constructed over the previous 1,3,6,12 months plus 2 through 6 and 7 through 12 months (see Novy-Marx, 2012).(A full set of portfolio results are available from the authors; the findings presented here are fully representative).The assets are equally weighted. All sector portfolios clearly dominate the long only results in Table 2 with far higher returns and Sharpe ratios; they also dominate the country momentum portfolios

\footnotetext{
${ }^{1}$ Bai and $\mathrm{Ng}$ (2008) show that the one-sided test for skewness, $\pi$, has a standard normal distribution under the null and has good power properties.
} 
which closely resemble the long only results in Table 2. There also seems to be some advantage in using recent memory calculation periods for momentum in the country analysis.

Risk weighting of assets in portfolio construction (see Ilmanen, 2011) has become increasingly popular among investment managers (see Asness, 2010). Here we repeat the above analysis but instead of ranking raw returns we rank by returns divided by risk. We employ realized volatility measures for constructing the inverse volatility weights using a window of days over which volatility is computed. This type of measure has been shown by Andersen and Bollerslev (1998), amongst others, to provide an unbiased and efficient measure of underlying volatility ${ }^{2}$. Given the monthly frequency of the returns data, we compute realized return volatility measures for 120 days prior to the date of the measurement of returns. Portfolio weights are then constructed to be proportional to the inverse of observed volatility. This process is repeated at the end of each month. This adjustment prevents the most volatile assets spending a disproportionate amount of time in the top momentum portfolios. Table 4 contain these results for sector and country separately. Again we show portfolios comprising the top 8 and top 4 assets. Once again, sector portfolios dominate country ones. There is very little to choose in terms of performance between the risk-adjusted momentum strategy and the standard version. Given the intuitive benefits of the former, though, we adopt this method for subsequent momentum calculations.

The results in Tables 3 and 4 show that a simple momentum strategy can improve on a buyand-hold portfolio, however, we note that both approaches have had to endure large drawdowns of in excess of 50\% during the period of study. The problem with both of these approaches is that they remain fully invested even when the market is falling - owning a portfolio of 'winners' is little consolation if, for example, they lose $45 \%$ when then market loses $47 \%$. Ideally, one would like to have less exposure to the market when it is displaying negative "time series momentum".

To address this we construct momentum portfolios as described earlier but they will only be owned when the current value of the Stoxx 600 index is above its trailing 10-month moving average; otherwise the portfolio is given over to cash and invested in 3-month Treasury Bills. The choice of moving average length is consistent with Faber (2007), however, that study also shows that other lengths between 6-12 months produce similar results. The choice of a 10-month moving average has a long empirical tradition in the study of CTA investing (eg

\footnotetext{
${ }^{2}$ Some alternatives are canvassed by Baltas and Kosowski (2013).
} 
see Hurst et al (2010); Clare et al (2014) explore a wide range of alterative specifications in this context. Table 5 shows the separate results for sectors and countries with a trend following overlay. There is a clear improvement in both returns and Sharpe ratios by incorporating trend following for both sector and country portfolios while maximum drawdowns are under a third of the long only models in Table 2. An investment strategy that incorporated a trend following element would have delivered significant benefits during the European crisis. Note that the short calculation periods now show no substantive improvement over longer periods. We also observe that the skewness of the portfolios changes substantially with the adoption of trend following, a feature common to the application of this technique in a wide range of contexts, including multi-asset and commodity investing (Clare et al, 2012, 2014). In Tables 2-4 the portfolios exhibit considerable negative skewness but in Table 5 most of this has been reversed with many now showing positive skew which the Bai-Ng tests is significant in some cases.

One intuitively appealing potential further improvement could involve a flexible approach combining both sectors and countries as they are ranked according to risk-adjusted momentum in a combined portfolio. Such a method has the benefit of requiring no prior judgement as to the relative merits of sectors versus countries. If the latter is performing well then they should appear higher up the momentum rankings and vice versa. The results appear in Table 6, again showing portfolios of the top 8 and top 4 countries/sectors. These combined momentum results are clearly inferior to the sector-only results in Table 3. However the overlaying of trend following on the combined portfolio (see Table 7) shows once again the power of trend following as a smoothing approach to portfolio returns; again Sharpe ratios almost double, maximum drawdown is cut by two-thirds, while returns are enhanced by 200300 pa basis points for all calculation periods. The risk-adjusted returns are now an improvement on the comparable standalone sector and country returns.

\subsection{Performance Prior to and Over the Crisis Period}

To illustrate the actual performance of the above strategies, Table 8 contains year by year returns from 1989 through 2011. Long-only (passive) strategies in columns 1 and 2, together with a volatility-weighted momentum portfolio in column 3, suffer large drawdowns around 2000-2002 and 2008. The really large improvement lies in the introduction of trend following in column 4. This strategy showed a loss of under $10 \%$ during the financial crisis year of 2008. Portfolios that remained fully invested during this period were forced to absorb losses 
that were around 50\%. From the perspective of an investor who was approaching a retirement and close to purchasing an annuity, such a substantial decline in portfolio value could dramatically affect their future living standards. Gray and Vogel (2013) point to such large drawdowns, which many equity investing strategies which claim to have uncovered "'anomalies" would have suffered in practice, and suggest that the violation of margin limits and other rules would have made such strategies impossible to see through to the successful capture of "alpha": this would not be the case for strategies embracing trend following.

In terms of countries versus sectors in combined momentum portfolios, Figure 1 plots the 3year average number of each appearing in the top 8 momentum portfolio over time. We note that prior to the year 2000, sectors and countries were represented in similar proportions. After this, though, sectors have a larger presence. Clearly during periods of extreme market volatility sectors appear to dominate as countries presumably become more correlated. One possible explanation for this is that the most recent crisis was a financial one, as opposed to the "dot-com crash" that, with the benefit of hindsight, was largely attributed to extreme valuations. Most countries have banks and other financial service companies that make up a sizeable weighting in their index. As a result when many of these institutions veered towards bankruptcy it caused many country's indices to decline precipitously. A sector investor was able to lose a little less by investing in some more defensive areas.

A distinction could also be made between how sector and country indices are formed. Taking the technology boom again of the late 1990's, the outsized gains of many internet and telecom stocks saw them promoted into "blue-chip" indices or, for those already there, their index weights substantially increased. As a result country indices effectively went 'overweight' a basket of very expensive stocks. From a sector perspective, however, this was less of an issue. For an investor who had an equal-weight in each industry group, they owned no more of these expensive sectors than they did before. This appears to be borne out by the outperformance of equal-weight sectors versus equal-weight countries in Table 2. The small gains from this, however, are dwarfed by the benefits of trend-following. 


\section{Explaining Strategy Returns and Downside Risk}

\subsection{Risk-adjusted returns}

The properties of returns presented thus far refer to unconditional returns from trend following and momentum strategies. In this section we examine whether these excess returns are explained by widely employed risk factors. For clarity, we examine the returns from particular selected strategies. These are the returns on a portfolio constructed from the top 8 (4) performing sector momentum returns where the 12-month trend following filter has also been applied and the returns on a portfolio constructed from the top 8 (4) performing sector and country momentum returns where the 12-month trend following filter has also been applied. ${ }^{3}$ The first four rows show results for equally weighted portfolio returns, whilst the final two rows show results for strategies where returns are volatility weighted.

In particular we examine estimates of alphas after regressing the returns from the strategies on two sets of risk factors which have been shown to explain substantial and significant amounts of the variation of returns in other markets; the Fama-French-Cahart four US equity market factors, MKT, SMB, HML and UMD and, secondly the Goldman -Sachs Commodity Index (GSCI), the world equity market return index (MSCI), Barclays Bond Index (BAR) and Dow-Jones Commodity Price Index (DJUBS) along with the five original hedge fund factors of Fung and Hsieh (2001): the PTFS Bond (SBD), Currency (SFX), Interest Rate (SIR), Stock Market (STK) and Commodity Trend (COM) lookback straddle returns; Whilst the Fama-French-Cahart factors have become a standard benchmark for many asset return models, the five factors found by Fung and Hsieh to explain hedge fund returns well also provide a suitable benchmark against which to judge the levels of returns for the various strategies shown above. We also report $\pi$, the Bai-Ng (2008) test for positive skewness in the raw returns.

The results of these estimates for the long-only strategies are shown in Table 9 where NeweyWest t-statistics are shown in square brackets. Looking across all of the strategy returns and risk factors, there is little evidence that exposure to these factors is able to account for the returns from the strategies. Comparison of the estimated alphas from the two risk adjustment regressions with the raw alpha shows that the alphas remain large and significantly larger than zero. In the case of the Fama-French-Cahart models in Panel A, the alphas are reduced

\footnotetext{
${ }^{3}$ These are the strategies whose performance is shown in the top (second) panel of Table 5 (fourth column) and in the top (second) panel of Table 7 (fourth column), respectively.
} 
by around one standard error of the estimates, that is that they are not significantly reduced once we allow for these standard sources of risk. Amongst the regressions the coefficients on the US equity market excess return and, perhaps unsurprisingly, the return to the Cahart momentum factor (UMD) are positive and individually significantly different to zero. The regressions for the Fama-French factors are jointly significant but explain little of the variation in returns in any case. For the more general models in Panel B, the alphas are essentially the same as in the unconditional case. In addition to the MSCI world equity market return index, amongst the Fung and Hsieh hedge fund factor the Commodity Trend lookback straddle return has a positive and marginally significant effect on the six portfolio returns as does negatively, the bond market factor and positively, the stock market factor for the various returns. These positive effects imply that the trend following and momentum strategies we examine are providing a hedge against the risks that these factors represent. These models explain somewhat less of the variation in returns than the Fama-French-Cahart model.

The analysis of risk explanations for the various combined momentum and trend following returns that we have found therefore suggests that whilst risk factors can provide a statistically significant contribution and explain some of the variation in returns, there remains a significant alpha which is at least two-thirds of the level of the raw excess returns and exceeds them in some cases.

\subsection{Downside risk}

We have shown that the standard and equally weighted index returns show significant downside negative skewness and substantial maximum drawdown over both of the periods that we examine. We have also shown that this negative skewness is reproduced in the case of momentum-only strategies. This feature of momentum returns was recently highlighted by Daniel and Moskowitz (2011) and Daniel et al (2012) who note that momentum strategy returns are often skewed and are subject to momentum crashes where momentum portfolio returns fall abruptly following a downturn in the market overall. The point being that momentum buying is based on a positive relative performance attribute, rather than an absolute one. This means that momentum buying continues in downturns, including severe downturns. A number of different approaches to understanding and combating downside risk have been examined in the literature. Strub (2013) compares two alternative solutions for tail risk, especially in the left tail. These are options or cash-based. Cash-based solutions were 
originally examined in the context of portfolio insurance in the 1980's, see Brennan and Schwatz (1989), for example. Strub (2013) shows, using simulations of data from the last decade, that options-based management of tail risk using widely-available traded options, has a significantly higher cost than cash-based strategies which allocate a fraction of portfolios to cash depending on measured Value at Risk compared with a target. The cash-based strategies generate higher returns for a given reduced level of volatility than the standard options-based alternatives. In this paper we show that trend-following strategies offer similar improvements in terms of reduced downside risk and maximum drawdown to those shown by Strub (2013): simple intuition would suggest that buying downside protection when volatility rises is bound to be expensive, whereas moving into cash is has no such pricing issues.

One possible explanation for this downside behaviour is exposure to global funding illiquidity. The idea is that funding constraints are likely to become important during financial crises at a time when we would expect global risk to increase as well as global risk aversion.

Brunnermeier and Pedersen (2009), Brunnermeier et al (2009) and Frazzini and Pedersen (2013) have examined a number of suitable measures for this illiquidity. We assess the responsiveness of the returns to the various strategies to one measure that these authors find to be a good candidate the TED spread: the difference between the LIBOR interbank interest rate and the risk-free Treasury Bill rate. The papers above use the original measure for the US economy, Given our interest in European equity markets, we adopt a more international measure, which is an equally weighted average of the equivalent of the TED spread for the US, UK, Australia and Euro for the full sample. These are the countries for which the variables concerned measure the equivalent of the US measure best. This global TED spread is similar in construction to that employed by Bakshi and Panayotov (2013) to successfully predict the return from the carry trade in the foreign exchange market. The LIBOR rate measures the cost of uncollateralized lending and reflects default risk. Liquidity problems in a national lending market result in expansion of the spread against the risk-free rate. Therefore, we would expect that equity returns would be negatively related to these periods of "flight to liquidity' 4

\footnotetext{
${ }^{4}$ The results we show all relate to the global TED spread. Unpublished estimate, available from the authors, show similar, but less significant, effects from models with the US TED spread alone.
} 
Table 10 shows the set of estimates of the sensitivity of the returns to various strategies to funding liquidity. These show that the standard index returns (Stoxx600 and MSCI Europe) are very sensitive to the change in the global TED spread. The very significant coefficient is negative and large as would be expected. The alpha on these index returns is also no longer significantly larger than zero. A similar sensitivity to the global TED spread can be seen in the return from the Top 8 sector, 2-6 month period momentum strategy from column 5 of Table 3 shown in row 3 . The alpha remains significant, and slightly larger than in the unconditional case. The results for the returns from the combined momentum and trend following strategies examined in Table 8 are quite different. None of the six returns is significantly related to the global TED spread. Again, the estimated alphas are slightly higher than in the unconditional case. This result is clearly related to the extent of the downside skewness in returns which we have already identified in the standard index and momentumonly returns. These results show that the use of trend following appears to reduce exposure to the impact of funding liquidity carried by the global TED spread.

\section{Conclusions}

In this paper we have extended previous analysis of the development of investment strategies which seek to reduce tail risk in volatile periods across European equity markets. We have shown that sector strategies dominate country strategies in the momentum portfolios that we construct. However the performance of momentum strategies in the recent financial crisis was very poor due to the large drawdowns experienced which would have proved intolerable to many investors or, indeed, would have led to forced liquidations as margin requirements were violated. We show that the addition of a simple and popular trend-following rule to a momentum strategy makes a huge difference to performance in terms of higher returns and Sharpe ratios as well as reduced maximum drawdown and skewness of returns. This improved performance is noticeable (at a more modest level) prior to the financial crisis. Finally, this paper contributes to the debate on the relative merits of sector versus countrybased strategies. We show that post-2000, sector strategies dominate. The novelty of our results is to show that this seems to be more closely related to developments in financial market volatility than to the introduction of the Euro per se.

We show that these results are not affected by exposure to sources of risk. The returns to the strategies that we examine show some significant exposure to traditional sources of risk from 
both the equity and other financial markets. We also examine the observed downside risk which is shown in index and momentum returns. We show that applying the trend-following filter reduces the downside risk in returns to a significant degree whilst delivering higher returns. We show that the index and momentum returns are also significantly sensitive to funding liquidity as measured by the world TED spread, whilst application of the trendfollowing filter removes this sensitivity. 


\section{References}

Adjaoute, K., Danthine, J.P., (2004). "Portfolio Diversification: Alive and Well in EuroLand!", Applied Financial Economics, 14, 1225-1231.

Antonacci, G., (2012). "Risk Premia Harvesting Through Momentum", Portfolio Management Associates.

ap Gwilym O., Clare, A., Seaton, J., Thomas, S., (2010). "Price and Momentum as Robust Tactical Approaches to Global Equity Investing", Journal of Investing, 19, 80-92.

Asness, C., Moskowitz, T., and Pedersen, L., (2010). "Value and Momentum Everywhere", AQR Working Paper

Baca, S., Garbe, B., Weiss, R., (2000). "The Rise of Sector Effects in Major Equity Markets", Financial Analysts Journal, 56, 34-40.

Bakshi, G. and Panayotov, G. (2013). "Predictability of Currency Carry Trades and Asset Pricing Implications", Journal of Finance.

Baltas, A. and Kosowski, R. (2013). "Momentum Strategies in Futures Markets and TrendFollowing Funds", Imperial College, London, mimeo.

Bartram, S., Karolyi, G., (2006). "The Impact of the Introduction of the Euro on Foreign Exchange Rate Risk Exposures", Journal of Empirical Finance, 13, 519-549.

Bekaert, G., Hoerova, M., Lo Duca, M., (2010) . "The European Union, the Euro and Equity Market Integration", NBER Working Paper.

Brennan, M. and Schwatz, E., (1989). "Portfolio and financial market equilibrium", Journal of Business, 62(4), 419-438.

Brunnermeier, M., Nagel, S., Pedersen, L., (2009). "Carry trades and currency crashes". NBER Macroeconomics Annual 23, 313-347.

Brunnermeier, M., Pedersen, L., (2009). "Market liquidity and funding liquidity". Review of Financial Studies, 22, 2201-2238.

Cavaglia, S., Brightman, C., Aked, M., (2000). "The Increasing Importance of Industry Factors", Financial Analysts Journal, 56, 5-14.

Clare, A., Seaton, J., Smith, P.N., Thomas, S., (2012). "The Trend is Our Friend: Risk Parity, Momentum and Trend Following in Global Asset Allocation", Cass Business School Working Paper.

Clare,A.,Seaton,J.,Smith,P.N.,and S Thomas(2014),' Breaking into the Blackbox', Journal of Asset Management,Forthcoming.

Daniel, K. and Moskowitz, T., (2011). "Momentum Crashes", Columbia Business School Research Paper.

Daniel, K., Jagannathan R. and Kim, S., (2012). "Tail Risk in Momentum Strategy Returns", NBER Working Paper 18169. 
De Santis, G., Gerard, B., (1998). "How Big is the Premium for Currency Risk?", Journal of Financial Economics, 49, 375-412.

Eiling, E., Gerard, B., De Roon, F., (2012). "Euro-Zone Equity Returns: Country Versus Industry Effects", Review of Finance, 16, 755-798.

Erb, C., and Harvey, C., (2006). "The Tactical and Strategic Value of Commodity Futures", Financial Analysts Journal, 62, 69-97.

Faber, M., (2007). “A Quantitative Approach to Tactical Asset Allocation", Journal of Wealth Management, 16, 69-79.

Faber, M., (2010)."Relative Strength Strategies for Investing", Cambria Investment Management Working Paper.

Ferreira, M.A., Ferreira, M.A., (2006). "The Importance of Industry and Country Effects in EMU Equity Markets", European Financial Management, 12, 341-373.

Flavin, T. (2004). "The Effect of the Euro on Country Versus Industry Portfolio Diversification", Journal of International Money and Finance, 23, 1137-1158.

Frazzini, A. and Pedersen, L., (2013). "Betting against Beta", mimeo.

Gray,W.R.,and Vogel,J., 'Using Maximum Drawdowns to Capture Tail Risk', http://papers.ssrn.com/sol3/papers.cfm?abstract_id=2226689

Grinblatt, M., and Moskowitz, T., (2004)."Predicting Stock Price Movements from Past Returns: The Role of Consistency and Tax-Loss Selling", Journal of Financial Economics, 541-579.

Hargis, K., Mei, J., (2006). "Is Country Diversification better than Industry Diversification?", European Financial Management, 12, 319-340.

Heston, S., Rouwenhorst, G., (1995). "Industry and Country Effects in International Stock Returns", Journal of Portfolio Management, 21, 53-58.

Hurst, B., Ooi, Y.H., Pedersen L., (2010). "Understanding Managed Futures", AQR Capital Management Working Paper.

Ilmanen A., (2011). Expected Returns. John Wiley \& Sons.

Jegadeesh, N. and Titman, S. (1993). "Returns to Buying Winners and Selling Losers: Implications for Stock Market Efficiency", Journal of Finance, 48, 65-91.

King, M., Silver, O., and Guo, B., (2002). "Passive Momentum Asset Allocation", Journal of Wealth Management, 5, 34-41.

Lessard, D., (1976). "World, Country and Industry Relationships in Equity Returns: Implications for Risk Reduction Through International Diversification", Financial Analysts Journal, 32, 32-38.

Levy, H., Sarnat M., (1970). "International Diversification of Investment Portfolios", American Economic Review, 60, 668-675. 
Miffre, J., Rallis, G., (2007), "Momentum Strategies in Commodity Futures Markets", Journal of Banking \& Finance, 31, 1863-1886.

Moskowitz, T., Ooi, Y.H., Pedersen L.H., (2011). "Time Series Momentum", University of Chicago Working Paper.

Novy-Marx, R. (2012). "Is Momentum Really Momentum?”, Journal of Financial Economics, 103, 429-453.

Ostgaard, S. (2008). "On the Nature of Trend Following", Last Atlantis Capital Management.

Solnik, B., (1974). "Why Not Diversify Internationally Rather Than Domestically?", Financial Analysts Journal, 30, 48-54.

Szakmary, A., Shen, Q., and Sharma, S., (2010). "Trend-Following Trading Strategies in Commodity Futures: A Re-Examination", Journal of Banking and Finance, 34, 409-426.

Strub,I.,(2013).“Tail hedging strategies”, Cambridge Strategy Ltd. http://ssrn.com/abstract=2261831

Wilcox, C. and Crittenden, E. (2005). "Does Trend-Following Work on Stocks?", BlackStar Funds. 
Table 1

\section{List of Sectors and Countries}

\begin{tabular}{ccccc}
\hline Sectors & \multicolumn{3}{c}{} & \\
\hline $\begin{array}{c}\text { Autos \& Parts } \\
\text { Financial Services } \\
\text { Media }\end{array}$ & $\begin{array}{c}\text { Banks } \\
\text { Food \& Beverage } \\
\text { Oil \& Gas } \\
\text { Telecoms }\end{array}$ & $\begin{array}{c}\text { Basic Resources } \\
\text { Health Care } \\
\text { Pers./House Goods } \\
\text { Travel \& Leisure }\end{array}$ & $\begin{array}{c}\text { Chemicals } \\
\text { Ind. Good/Services } \\
\text { Real Estate } \\
\text { Utilities }\end{array}$ & $\begin{array}{c}\text { Construction/Mats. } \\
\text { Insurance } \\
\text { Retail }\end{array}$ \\
\hline Countries & Belgium & Denmark & Finland & France \\
Austria & Ireland & Italy & Netherlands & Norway \\
Germany & Spain & Sweden & Switzerland & United Kingdom \\
\hline
\end{tabular}


Table 2

Summary Statistics for Standard Indices and Equal-Weight Portfolios

\begin{tabular}{lcccc}
\hline & Stoxx 600 & MSCl Europe & EW Stoxx & EW MSCl \\
\hline Annualized Return (\%) & 7.96 & 7.59 & 8.90 & 7.75 \\
Annualized Volatility (\%) & 18.04 & 18.00 & 18.21 & 19.01 \\
Sharpe Ratio & 0.24 & 0.22 & 0.29 & 0.22 \\
Max. Monthly Return (\%) & 14.05 & 13.94 & 15.80 & 15.02 \\
Min. Monthly Return (\%) & -21.63 & -21.24 & -21.09 & -24.93 \\
Maximum Drawdown (\%) & 59.34 & 59.29 & 58.70 & 63.62 \\
Skew & -0.56 & -0.53 & -0.55 & -0.72 \\
$\Pi(* *$ sig at 95\%, *90\%) & $-1.69^{* *}$ & $-1.66^{* *}$ & $-1.77^{* *}$ & $-1.58^{*}$ \\
& & & & \\
\hline
\end{tabular}


Table 3

\begin{tabular}{|c|c|c|c|c|c|c|}
\hline \multicolumn{7}{|c|}{ Sector and Country Momentum } \\
\hline & \multicolumn{6}{|c|}{ Calculation Period (months) } \\
\hline & 1 & 3 & 6 & 12 & $2-6$ & $7-12$ \\
\hline \multicolumn{7}{|l|}{ Top 8 - Sector } \\
\hline Annualized Return (\%) & 12.37 & 11.36 & 10.72 & 10.55 & 9.35 & 10.68 \\
\hline Annualized Volatility (\%) & 18.12 & 17.30 & 17.46 & 17.58 & 17.98 & 18.35 \\
\hline Sharpe Ratio & 0.48 & 0.45 & 0.41 & 0.39 & 0.32 & 0.38 \\
\hline Max. Monthly Return (\%) & 22.23 & 13.72 & 13.69 & 15.49 & 15.36 & 16.12 \\
\hline Min. Monthly Return (\%) & -17.64 & -17.76 & -18.02 & -18.61 & -20.94 & -20.36 \\
\hline Maximum Drawdown (\%) & 55.00 & 53.34 & 53.25 & 51.83 & 56.47 & 57.07 \\
\hline Skew & -0.28 & -0.44 & -0.47 & -0.52 & -0.60 & -0.51 \\
\hline$\Pi(* *$ sig at $95 \%, * 90 \%)$ & -1.00 & $-1.92^{* *}$ & $-1.64^{* *}$ & $-1.75^{* *}$ & $-1.47^{*}$ & $-1.83 * *$ \\
\hline \multicolumn{7}{|l|}{ Top 4 - Sector } \\
\hline Annualized Return (\%) & 12.19 & 12.11 & 10.73 & 11.52 & 9.42 & 9.75 \\
\hline Annualized Volatility (\%) & 19.15 & 18.12 & 18.20 & 18.90 & 18.69 & 19.69 \\
\hline Sharpe Ratio & 0.45 & 0.47 & 0.39 & 0.42 & 0.31 & 0.31 \\
\hline Max. Monthly Return (\%) & 26.74 & 16.45 & 19.56 & 21.92 & 18.26 & 18.77 \\
\hline Min. Monthly Return (\%) & -14.75 & -15.82 & -14.67 & -20.93 & -17.69 & -22.88 \\
\hline Maximum Drawdown (\%) & 53.81 & 53.22 & 52.82 & 56.96 & 55.06 & 59.10 \\
\hline Skew & 0.20 & -0.18 & -0.11 & -0.41 & -0.20 & -0.53 \\
\hline$\Pi(* *$ sig at $95 \%, * 90 \%)$ & 0.53 & -0.93 & -0.50 & -1.07 & -0.86 & $-1.37 *$ \\
\hline \multicolumn{7}{|l|}{ Top 8 - Country } \\
\hline Annualized Return (\%) & 7.85 & 7.50 & 8.41 & 9.78 & 8.46 & 10.83 \\
\hline Annualized Volatility (\%) & 19.25 & 18.79 & 19.04 & 18.75 & 19.44 & 19.06 \\
\hline Sharpe Ratio & 0.22 & 0.21 & 0.25 & 0.33 & 0.25 & 0.38 \\
\hline Max. Monthly Return (\%) & 15.63 & 14.28 & 14.35 & 14.87 & 14.35 & 14.50 \\
\hline Min. Monthly Return (\%) & -22.31 & -22.11 & -22.04 & -22.04 & -24.74 & -24.57 \\
\hline Maximum Drawdown (\%) & 64.36 & 61.36 & 62.08 & 58.79 & 63.58 & 61.67 \\
\hline Skew & -0.63 & -0.58 & -0.62 & -0.59 & -0.66 & -0.67 \\
\hline$\Pi(* *$ sig at $95 \%, * 90 \%)$ & $-1.69 * *$ & $-1.81^{* *}$ & $-1.44 *$ & $-1.59 *$ & $-1.47^{*}$ & $-1.39 *$ \\
\hline \multicolumn{7}{|l|}{ Top 4 - Country } \\
\hline Annualized Return (\%) & 8.79 & 7.75 & 8.96 & 10.73 & 8.54 & 10.83 \\
\hline Annualized Volatility (\%) & 20.31 & 20.11 & 19.88 & 20.13 & 20.48 & 20.63 \\
\hline Sharpe Ratio & 0.25 & 0.20 & 0.27 & 0.35 & 0.24 & 0.35 \\
\hline Max. Monthly Return (\%) & 16.87 & 16.53 & 16.56 & 16.56 & 16.56 & 16.27 \\
\hline Min. Monthly Return (\%) & -21.56 & -21.56 & -19.15 & -21.56 & -22.56 & -22.38 \\
\hline Maximum Drawdown (\%) & 62.20 & 61.72 & 61.67 & 63.73 & 63.84 & 63.16 \\
\hline Skew & -0.48 & -0.38 & -0.48 & -0.55 & -0.48 & -0.60 \\
\hline$\Pi(* *$ sig at $95 \%, * 90 \%)$ & $-1.37^{*}$ & $-1.56^{*}$ & $-1.67^{* *}$ & $-1.71^{* *}$ & -1.27 & $-1.42 *$ \\
\hline
\end{tabular}


Table 4

Sector and Country Risk-Adjusted Momentum

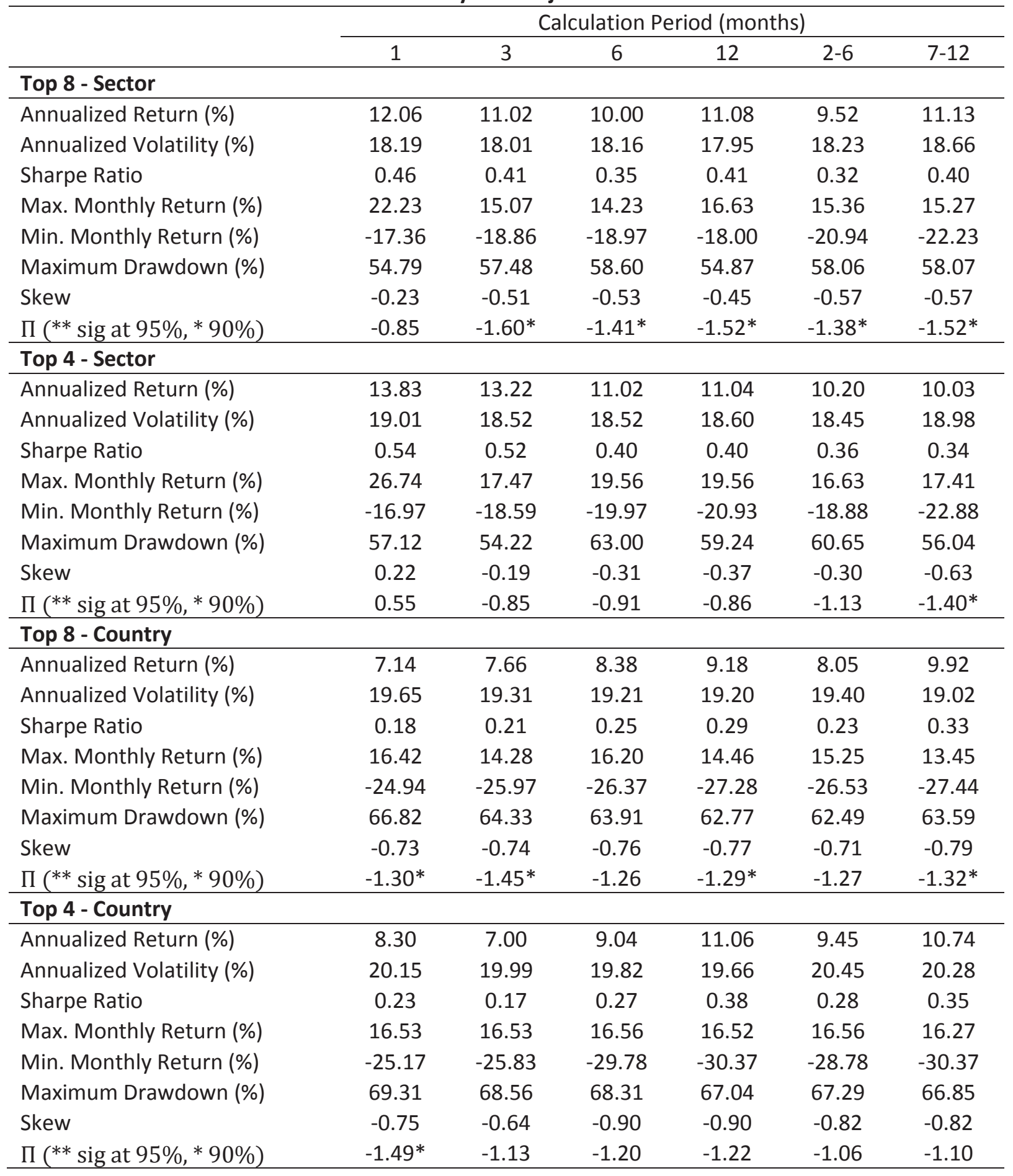


Table 5

\begin{tabular}{|c|c|c|c|c|c|c|}
\hline \multicolumn{7}{|c|}{ Stoxx Sector Risk-Adjusted Momentum with Trend Following Overlay } \\
\hline & \multicolumn{6}{|c|}{ Calculation Period (months) } \\
\hline & 1 & 3 & 6 & 12 & $2-6$ & $7-12$ \\
\hline \multicolumn{7}{|l|}{ Top 8 - Sector } \\
\hline Annualized Return (\%) & 12.12 & 13.27 & 12.92 & 13.35 & 12.29 & 12.73 \\
\hline Annualized Volatility (\%) & 11.62 & 12.09 & 12.32 & 12.08 & 12.03 & 11.36 \\
\hline Sharpe Ratio & 0.73 & 0.80 & 0.75 & 0.80 & 0.72 & 0.80 \\
\hline Max. Monthly Return (\%) & 13.15 & 13.21 & 14.23 & 15.49 & 12.62 & 14.19 \\
\hline Min. Monthly Return (\%) & -12.28 & -13.86 & -13.86 & -13.03 & -13.02 & -10.26 \\
\hline Maximum Drawdown (\%) & 17.10 & 14.77 & 17.66 & 17.78 & 18.87 & 17.73 \\
\hline Skew & 0.01 & 0.09 & 0.09 & 0.19 & 0.05 & 0.28 \\
\hline$\Pi(* *$ sig at $95 \%, * 90 \%)$ & 0.05 & 0.27 & 0.30 & 0.60 & 0.19 & 1.01 \\
\hline \multicolumn{7}{|l|}{ Top 4 - Sector } \\
\hline Annualized Return (\%) & 13.40 & 14.59 & 13.94 & 13.78 & 13.43 & 12.57 \\
\hline Annualized Volatility (\%) & 12.67 & 12.92 & 13.47 & 13.08 & 13.19 & 11.85 \\
\hline Sharpe Ratio & 0.77 & 0.85 & 0.76 & 0.78 & 0.74 & 0.75 \\
\hline Max. Monthly Return (\%) & 21.48 & 16.45 & 19.56 & 19.56 & 16.59 & 14.99 \\
\hline Min. Monthly Return (\%) & -12.00 & -11.45 & -12.38 & -12.00 & -11.95 & -11.98 \\
\hline Maximum Drawdown (\%) & 15.20 & 14.97 & 19.85 & 18.69 & 18.77 & 13.34 \\
\hline Skew & 0.77 & 0.46 & 0.52 & 0.59 & 0.38 & 0.48 \\
\hline$\Pi(* *$ sig at $95 \%, * 90 \%)$ & 1.27 & $1.48^{*}$ & 1.27 & $1.35^{*}$ & 1.21 & $1.58 *$ \\
\hline \multicolumn{7}{|l|}{ Top 8 - Country } \\
\hline Annualized Return (\%) & 11.52 & 12.26 & 11.75 & 12.31 & 11.66 & 12.03 \\
\hline Annualized Volatility (\%) & 11.98 & 12.33 & 12.39 & 12.25 & 12.24 & 11.33 \\
\hline Sharpe Ratio & 0.66 & 0.70 & 0.65 & 0.71 & 0.66 & 0.74 \\
\hline Max. Monthly Return (\%) & 11.90 & 11.90 & 11.90 & 13.61 & 12.37 & 11.53 \\
\hline Min. Monthly Return (\%) & -14.97 & -14.82 & -14.82 & -14.31 & -14.76 & -13.13 \\
\hline Maximum Drawdown (\%) & 17.66 & 15.01 & 19.31 & 18.90 & 18.29 & 15.89 \\
\hline Skew & -0.02 & 0.03 & -0.10 & -0.06 & -0.11 & -0.06 \\
\hline$\Pi(* *$ sig at $95 \%, * 90 \%)$ & -0.04 & 0.08 & -0.30 & -0.17 & -0.32 & -0.16 \\
\hline \multicolumn{7}{|l|}{ Top 4- Country } \\
\hline Annualized Return (\%) & 12.85 & 11.95 & 13.34 & 14.31 & 12.49 & 13.32 \\
\hline Annualized Volatility (\%) & 12.93 & 13.38 & 13.11 & 13.28 & 13.20 & 12.65 \\
\hline Sharpe Ratio & 0.71 & 0.62 & 0.74 & 0.80 & 0.67 & 0.77 \\
\hline Max. Monthly Return (\%) & 16.53 & 16.53 & 16.56 & 16.52 & 16.56 & 16.27 \\
\hline Min. Monthly Return (\%) & -14.55 & -14.76 & -13.71 & -14.22 & -13.71 & -14.79 \\
\hline Maximum Drawdown (\%) & 20.40 & 17.44 & 18.96 & 18.53 & 20.74 & 21.75 \\
\hline Skew & 0.19 & 0.15 & 0.16 & 0.15 & 0.03 & 0.17 \\
\hline$\Pi(* *$ sig at $95 \%, * 90 \%)$ & 0.49 & 0.43 & 0.48 & 0.41 & 0.09 & 0.38 \\
\hline
\end{tabular}


Table 6

Sector and Country Combined Risk-Adjusted Momentum

\begin{tabular}{lcccccc}
\hline & \multicolumn{7}{c}{ Calculation Period (months) } \\
\cline { 2 - 7 } & 1 & 3 & 6 & 12 & $2-6$ & $7-12$ \\
\hline Top 8 - All & & & & & & \\
\hline Annualized Return (\%) & 10.85 & 10.55 & 10.41 & 11.52 & 10.14 & 10.90 \\
Annualized Volatility (\%) & 18.69 & 18.54 & 18.62 & 18.62 & 19.04 & 18.62 \\
Sharpe Ratio & 0.39 & 0.37 & 0.36 & 0.42 & 0.34 & 0.39 \\
Max. Monthly Return (\%) & 22.22 & 16.49 & 18.06 & 20.29 & 17.58 & 15.77 \\
Min. Monthly Return (\%) & -19.55 & -19.65 & -20.51 & -23.78 & -24.69 & -24.25 \\
Maximum Drawdown (\%) & 59.45 & 60.57 & 63.15 & 61.72 & 64.29 & 57.89 \\
Skew & -0.24 & -0.43 & -0.57 & -0.61 & -0.61 & -0.71 \\
П (** sig at 95\%, *90\%) & -0.74 & -1.12 & -1.23 & -1.09 & -1.12 & $-1.50 *$ \\
\hline Top 4 - All & & & & & & \\
\hline Annualized Return (\%) & 11.44 & 10.67 & 12.54 & 12.35 & 12.06 & 9.89 \\
Annualized Volatility (\%) & 19.72 & 19.12 & 19.25 & 19.16 & 19.48 & 19.62 \\
Sharpe Ratio & 0.40 & 0.37 & 0.46 & 0.45 & 0.43 & 0.32 \\
Max. Monthly Return (\%) & 24.10 & 24.21 & 21.82 & 22.54 & 21.82 & 20.46 \\
Min. Monthly Return (\%) & -17.12 & -18.59 & -19.58 & -22.26 & -19.58 & -23.06 \\
Maximum Drawdown (\%) & 60.04 & 61.33 & 66.35 & 60.99 & 64.16 & 60.19 \\
Skew & -0.04 & -0.15 & -0.37 & -0.36 & -0.25 & -0.58 \\
П (** sig at 95\%, *90\%) & -0.14 & -0.38 & -0.90 & -0.66 & -0.69 & $-1.31 *$ \\
\hline
\end{tabular}


Table 7

Sector and Country Combined Risk-Adjusted Momentum with Trend Following Overlay

\begin{tabular}{lcccccc}
\hline & \multicolumn{7}{c}{ Calculation Period (months) } \\
\cline { 2 - 7 } & 1 & 3 & 6 & 12 & $2-6$ & $7-12$ \\
\hline Top 8 - All & & & & & & \\
\hline Annualized Return (\%) & 13.19 & 13.56 & 13.55 & 14.59 & 13.29 & 13.35 \\
Annualized Volatility (\%) & 12.81 & 12.69 & 12.89 & 12.94 & 13.07 & 12.30 \\
Sharpe Ratio & 0.75 & 0.78 & 0.77 & 0.85 & 0.74 & 0.79 \\
Max. Monthly Return (\%) & 19.00 & 16.49 & 18.06 & 20.29 & 17.58 & 15.30 \\
Min. Monthly Return (\%) & -13.86 & -13.10 & -13.04 & -13.72 & -12.43 & -13.08 \\
Maximum Drawdown (\%) & 17.60 & 17.10 & 17.85 & 18.00 & 20.14 & 22.30 \\
Skew & 0.36 & 0.28 & 0.36 & 0.52 & 0.35 & 0.10 \\
П (** sig at 95\%, *90\%) & 0.75 & 0.79 & 0.93 & 1.01 & 1.01 & 0.31 \\
\hline Top 4 - All & & & & & & \\
\hline Annualized Return (\%) & 14.74 & 15.06 & 15.84 & 15.17 & 15.22 & 12.80 \\
Annualized Volatility (\%) & 14.01 & 13.55 & 13.93 & 14.05 & 13.93 & 13.63 \\
Sharpe Ratio & 0.79 & 0.84 & 0.88 & 0.82 & 0.83 & 0.67 \\
Max. Monthly Return (\%) & 19.34 & 24.21 & 21.82 & 22.54 & 21.82 & 20.46 \\
Min. Monthly Return (\%) & -14.03 & -9.81 & -10.96 & -13.19 & -12.32 & -14.37 \\
Maximum Drawdown (\%) & 17.37 & 16.60 & 17.74 & 20.47 & 19.92 & 22.20 \\
Skew & 0.56 & 0.99 & 0.66 & 0.82 & 0.68 & 0.33 \\
П (** sig at 95\%, * 90\%) & 0.80 & 0.85 & 1.21 & $1.31 *$ & $1.40 *$ & 0.71 \\
\hline
\end{tabular}


Table 8

\section{Strategy Returns by Year}

\begin{tabular}{ccccc}
\hline Year & Stoxx 600 & $\begin{array}{c}\text { Equal Weight All } \\
\text { Sectors \& } \\
\text { Countries }\end{array}$ & $\begin{array}{c}\text { Risk-Adjusted } \\
\text { Momentum Top 8 }\end{array}$ & $\begin{array}{c}\text { Risk-Adjusted } \\
\text { Momentum with } \\
\text { Trend Following }\end{array}$ \\
\hline 1989 & 29.7 & 32.3 & 40.6 & 40.6 \\
1990 & -2.4 & -7.1 & -4.7 & 5.2 \\
1991 & 13.0 & 9.7 & 15.9 & -8.9 \\
1992 & -4.5 & -7.5 & -2.2 & 6.7 \\
1993 & 29.4 & 34.5 & 32.8 & 25.4 \\
1994 & 3.1 & 6.8 & 8.3 & -2.4 \\
1995 & 21.9 & 18.8 & 23.5 & 23.3 \\
1996 & 22.9 & 23.7 & 22.5 & 22.5 \\
1997 & 23.6 & 20.8 & 22.7 & 22.7 \\
1998 & 28.9 & 28.2 & 37.1 & 25.8 \\
1999 & 18.2 & 16.3 & 37.9 & 30.1 \\
2000 & -10.0 & -7.8 & -17.2 & -4.3 \\
2001 & -20.5 & -16.4 & -17.9 & 3.4 \\
2002 & -18.2 & -16.1 & -2.3 & 5.6 \\
2003 & 40.6 & 43.5 & 33.7 & 30.2 \\
2004 & 21.0 & 26.2 & 38.0 & 27.7 \\
2005 & 9.9 & 11.0 & 12.6 & 12.6 \\
2006 & 35.0 & 38.9 & 41.5 & 41.5 \\
2007 & 13.5 & 14.2 & 15.7 & 15.7 \\
2008 & -46.5 & -48.8 & -51.5 & -8.9 \\
2009 & 36.6 & 38.8 & 39.2 & 26.9 \\
2010 & 4.4 & 6.5 & 12.8 & 8.3 \\
2011 & -11.6 & -13.6 & -6.7 & 7.4 \\
\hline & & & & \\
\hline
\end{tabular}




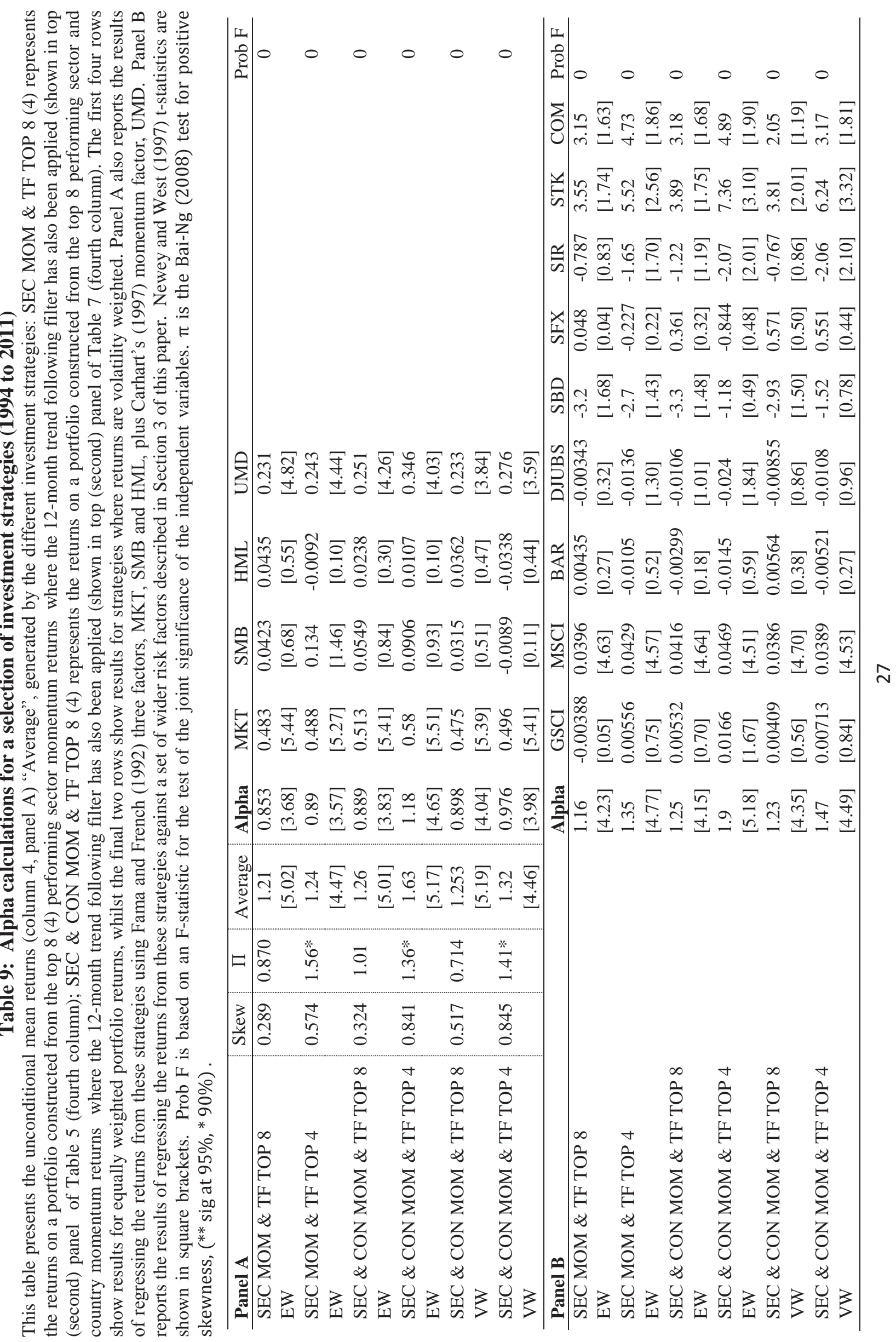




\begin{tabular}{|c|c|c|}
\hline & Alpha & dTED \\
\hline \multirow[t]{2}{*}{ STOXX600 } & 0.729 & -3.280 \\
\hline & [1.84] & [3.04] \\
\hline \multirow[t]{2}{*}{ MSCI Eur } & 0.709 & -7.982 \\
\hline & [1.86] & {$[3.20]$} \\
\hline \multirow{2}{*}{ MOM } & 0.993 & -7.832 \\
\hline & [2.77] & [3.31] \\
\hline \multirow[t]{2}{*}{ SEC MOM \& TF TOP 8 EW } & 1.222 & -3.407 \\
\hline & [5.04] & {$[1.46]$} \\
\hline \multirow[t]{2}{*}{ SEC MOM \& TF TOP 4 EW } & 1.261 & -4.536 \\
\hline & [4.56] & {$[1.71]$} \\
\hline \multirow[t]{2}{*}{ SEC \& CON MOM \& TF TOP 8 EW } & 1.274 & -3.679 \\
\hline & {$[5.05]$} & [1.39] \\
\hline \multirow[t]{2}{*}{ SEC \& CON MOM \& TF TOP 4 EW } & 1.656 & -4.447 \\
\hline & {$[5.25]$} & [1.61] \\
\hline \multirow[t]{2}{*}{ SEC \& CON MOM \& TF TOP 8 VW } & 1.264 & -3.281 \\
\hline & [5.24] & {$[1.42]$} \\
\hline \multirow[t]{2}{*}{ SEC \& CON MOM \& TF TOP 4 VW } & 1.334 & -3.355 \\
\hline & [4.05] & [1.44] \\
\hline
\end{tabular}




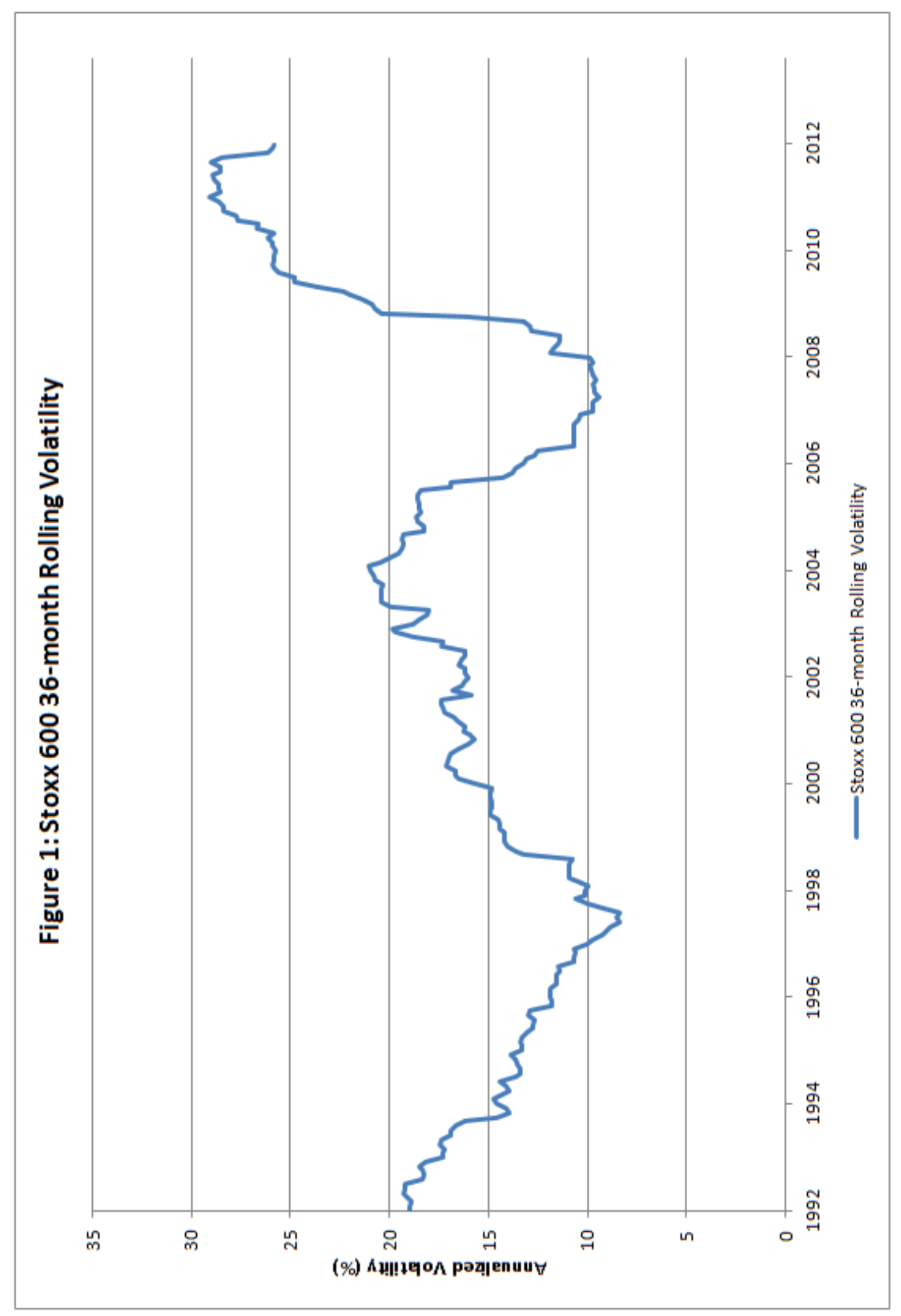




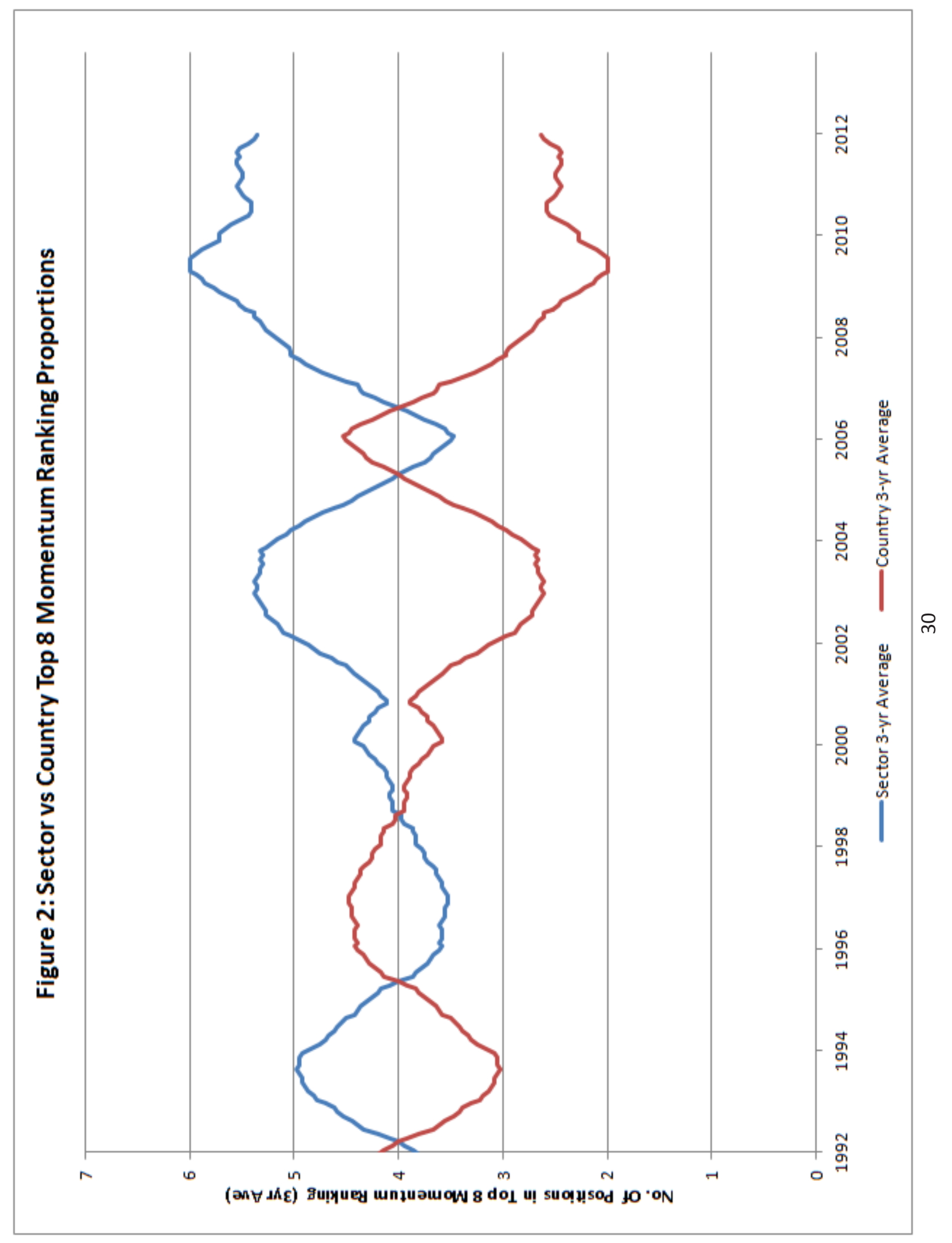

